\title{
INVESTIGATION OF FATIGUE DAMAGE IN GENERAL, PRESTRESS, AND CONCRETE BEAM REINFORCED WITH FRP SHEETS AND CONCRETE BEAM INFLUENCED BY MIX BEAM UNDER PERIODIC LOAD IN LINEAR AND NONLINEAR PHASE
}

\author{
JEDKAREH O. ${ }^{\text {a,*, }}$, GHOLI ZAD A. ${ }^{\text {b }}$ \\ a,* University of Hormozgan, Department of Civil Engineering, Bandar Abbas, Iran, e-mail: omid.jedkareh@gmail.com \\ b Mohagheghe Ardebili University, Department of Civil Engineering, Ardebil, Iran, e-mail: gholizad@ uma.ac.ir
}

Received: 05.03.2019 / Accepted: 11.04.2019 / Revised: 11.05.2019 / Available online: 31.05.2019

DOI: 10.2478/jaes-2019-0010

KEY WORDS: Fatigue, Prestress Concrete, FRP, Bridge Cable, Abaqus.

\begin{abstract}
:
Reinforcement of concrete components using FRP is one of the new strengthening methods that replaces old methods such as steel or concrete reinforcement. In spite of the extensive research on numerical analysis (limited components) of the behavior of components of reinforced concrete, few studies have been done on components of prestress concrete and its components limited modelling. In this study, using the Abaqus software, the behavior of four samples of concrete beams under periodic load, including original, prestress, reinforced with FRP sheets and influenced by both prestress and reinforced with FRP sheets (mix beam) was modelled. Prestress in structural fatigue showed that in both loading and unloading conditions, the prestress beam is more strength than the original beam.
\end{abstract}

\section{INTRODUCTION}

Prestress concrete for overcoming the problem of cracking in reinforced concrete was first recorded by Durens Francisco in 1886 (Nardone et al. 2012, Dai et al., 2016). Prestress concrete stretches reinforced steel before concreting and prestress is applied to the bond formed between reinforced steel and hardened concrete (Martí et al. 2014, Abdelatif et al., 2015). While in poststress technique, reinforced steel or tendon is stretched after concreting and obtaining proper strength. Prestress concrete is mostly used in the building structures in production of beams and slabs (Huang et al., 2015, Dewit, 2012).

These beams are usually produced for better quality control in the factory, and in large openings, concrete beams are mostly used. Prestress structure systems under recurrent and natural forces, such as earthquakes, often show considerable nonlinear and hysterical behavior. (Li et al., 2018, Bu et al., 2015). In these conditions, the falls that may occur in prestress steels are short-term and long-term falls. Long-term falls relate to the time function of prestress steel and concrete. Creep and fall in concrete will increase the strain and consequently crackup. Fatigue damage in concrete is due to frictional erosion and bumpiness and swelling, or due to an inappropriate design considering large thickness against a small cross-section (Wada et al., 2006).
Reinforcement of concrete components using FRP is one of the new strengthening methods that replaces old methods such as steel or concrete reinforcement. Balaguru et al. (2012) In spite of the extensive research on numerical analysis (limited components) of the behavior of components of reinforced concrete, few studies have been done on components of prestress concrete and its components limited modelling. Wolanski et al. (2004) studied the behavior of ordinary reinforced and prestress concrete beams using limited components analysis for studying the load-displacement behavior of these components. In the first stage, a typical reinforced concrete beam was modelled in ANSYS software and the results of this model was compared with the experimental results of the other research.

In the second stage, for modelling of a prestress beam, the parameters of modelled concrete of previous stage were used, and the specific points of the load curve - displacement predicted by limited component analysis were compared with theoretical results. The results were according to experimental and theoretical results. Ludovico et al. (2003) conducted experiments at the University of Missouri-Rolla to investigate the effect of strengthening main prestress beams damaged by FRP sheets. Experiments on three samples - one sample without damage and two samples damaged and reinforced with FRP sheets (with different amounts of damage and strengthening) showed that the strengthening method by FRP

\footnotetext{
*Corresponding author: JEDKAREH Omid, e-mail: omid.jedkareh@ gmail.com
} 
sheets was effective in structural design and was able to retrieve flexural and the hardness of the beam without damage (controlled sample), for damaged samples. The use of prestress FRP in concrete structures is possible by using prestress FRP set inside concrete, prestress FRP sheets adhered to the outer surface of concrete and prestress beams. Specifications of materials including steel rod:

$$
E_{x t}=2.05 \times 10^{5} \mathrm{~N} / \mathrm{mm}^{2}, v=0.3, \rho=7.85 \times 10^{-6} \mathrm{~kg} / \mathrm{mm}^{3}
$$

FRP is mounted near surface concrete (NSM). Maes et al. (2001) presented an analytical framework for developing relationships between fatigue in prestress concrete bridges and tension corrosion progression (SSC). The SSC model considers degrees of material sensitivity, stresses, and environmental conditions, and is made up of three steps: small cracking, propagation and instability of large cracks using linear elastic fracture mechanics. The results of the study showed that the important parameters in the evaluation of the fatigue reliability framework are size and exacerbation of the corrosive environment, the average truck traffic, and the uncertainty in the physical model of SCC, the uncertainty in the long SN model, and the tail-modelling function, probability of distributing truck loads. Zia et al. (2002) examined the fatigue action in width of main prestress concrete beams in large-scale, damaged by transverse gaps.

The results showed that loading fatigue does not really affect the behavior of main beams. No erosion was observed in the hardness or strength of the shafters after 1,200, and 500 cycles of fatigue loading. Alampalli et al. (2010) in his research attempts to predict fatigue life by reducing the uncertainty in traffic loading, and ultimately obtains a longer theoretical service for bridges. The results showed that many identified critical details have a certain fatigue life, and the remains a considerable fatigue life. The hysteresis and energy time diagrams for each of the mentioned models were analysed.

\section{METHODOLOGY}

In this research, the effect of load transfer, load distribution on bridge legs and the ratio of bending anchor to axial force is investigated. The studied design is for prestressed united bridges which were analyzed with Abaqus. The analysis has been carried out for elements of beam or distribution of cracks in the elements (causing small cracks to prevent large cracks), for prestress steel and transferring force in entering to concrete. Using Abaqus software version 6.14-2, behavior of four types of beams have been modeled including Model 1: General Beam under periodic load (fatigue load), Model 2: Prestress beam under periodic load (fatigue loading), Model 3: beam reinforced with FRP sheets under wheel load (fatigue loading) and Model 4: beam under the influence of pre-stress and reinforced with FRP (Mix Beam) under a periodic load (fatigue loading). The results were analyzed in hysteresis and time diagrams of the energy system for each of the models listed.

In order to ensure the correctness of the modelling, including loading, reciprocal conditions, materials and interactions of the materials, the output of the software were compared with laboratory results. Prestress beam at the laboratory was placed under static load and modelled by the Abaqus software. This beam has a rectangular cross section in $2000 * 200 * 2000 \mathrm{~mm}$. The beam has two cables, in $5 \mathrm{~mm}$ diameter, which have been prestressed till 1010 mega pascal. The tendon elastic modulus is assumed 200 Giga Pascal. The results of modelling indicate that the accuracy of the proposed model in predicting the behavior of this beam is accepted. The geometric characteristics of prestress beam are shown in Figure 1.

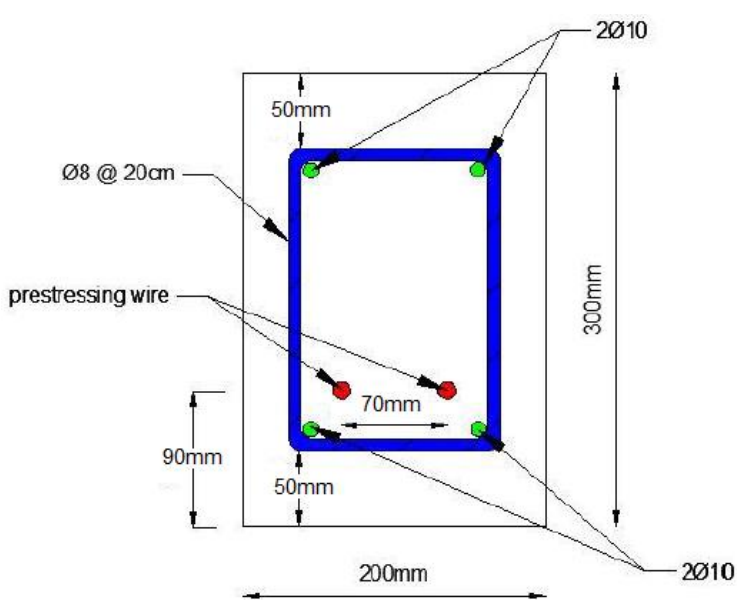

Figure 1. Geometric characteristics of the cross section

With strength stress, steel rod is $400 \mathrm{MPa}$. Prestress cable with an elastic modulus is $200 \mathrm{GPa}$ and its strength stress is $1680 \mathrm{MPa}$. This cable is prestressed to $1010 \mathrm{MPa}$ stress. In the Abaqus software, three kinds of modeling cracks can be modeled for material damage, in this research concrete damage plasticity model is used. This method uses Drucker Prager's theory. In this theory, the failure is calculated through depreciation of energy and boundary levels.

FRP sheets consist of one-side fibers. In other words, the mechanical properties of these materials will be different in different directions. The lamina option is used to define the elastic properties of materials. Thus, materials are definite with sheet stress behavior, and different characteristics in different directions.

The figures of geometry in concrete beam, FRP sheet, rods, and sampled beam model are presented in Figure. 2.
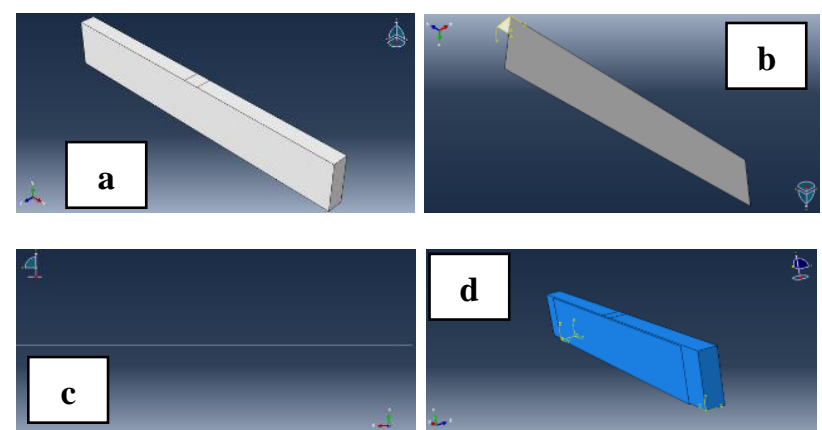

Figure 2. (a) Geometry (b) Concrete beam (c) FRP sheets and (d) Rods assembled model of the beam with FRP sheet and buried rods in concrete 


\subsection{Loading and fulcrum conditions}

The distance among fulcrums is $1800 \mathrm{~mm}$, and loading is along the $y$ axis. Prestress in cable was done at this stage. In the Abacus software for applying the fatigue effect to the prestress beams which a cyclic loading was done on the beams. Loading is done by moving of structure, in the middle of the mouth of the beam.

\subsection{Mesh}

Before model analysis, the structure is meshed. The type of element in the program for concrete is C3D8R, which is solid and 8-nodal with reduced integration. For rods considered element is T3D2 which is Truss, three-dimensional and twonodal. For FRP, considered element is S4R which is element of 4-nodal sheets with reduced integration. Figures of meshing in beams, FRP sheets and bars are presented in Figure 3.

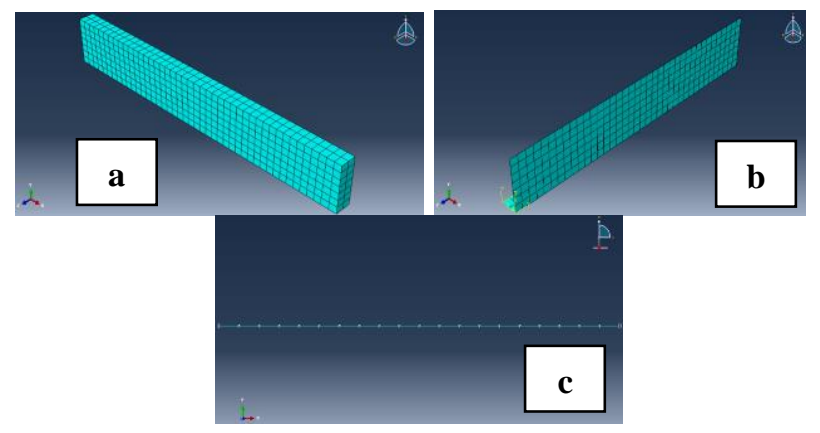

Figure 3. (a) Mesh concrete, (b) FRP sheets and (c) Rods

\section{RESULTS}

\subsection{Contour stresses}

The rod stress contour is presented in Figure 4a. It is observed that the prestress cable can withstand most stresses of $1680 \mathrm{~N} /$ $\mathrm{mm} 2$. The concrete tension contour is presented in Figure $4 \mathrm{~b}$. Concrete withstands the highest stress in loading place in the middle of the mouth, also in the fulcrums, which is $55.63 \mathrm{~N} /$ $\mathrm{mm} 2$. The displacement contour in rod is shown in Figure c4. The largest displacement occurs in loading place in the middle of the mouth, which is $30.74 \mathrm{~mm}$. The displacement contour in concrete is shown in Figure c4. The largest displacement occurs in loading place in the middle of the mouth, which is $32.76 \mathrm{~mm}$ (Figure 4).

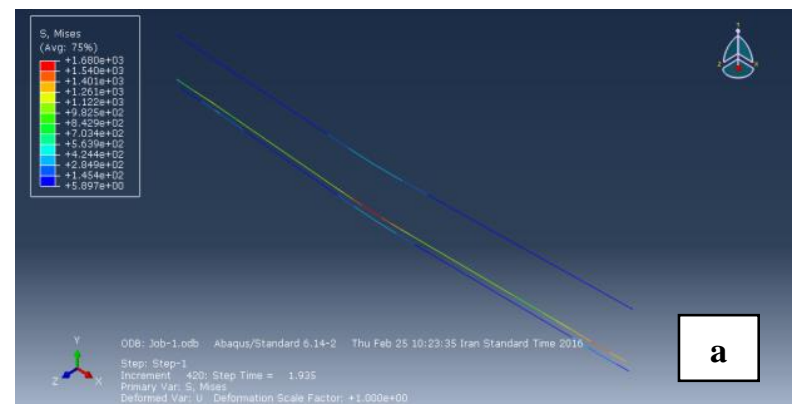

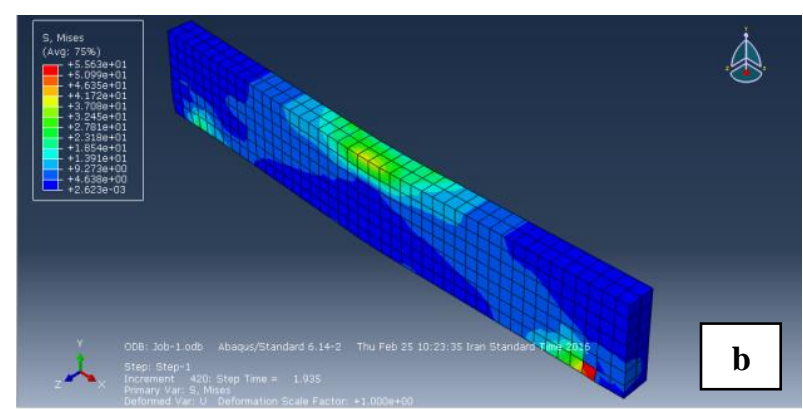
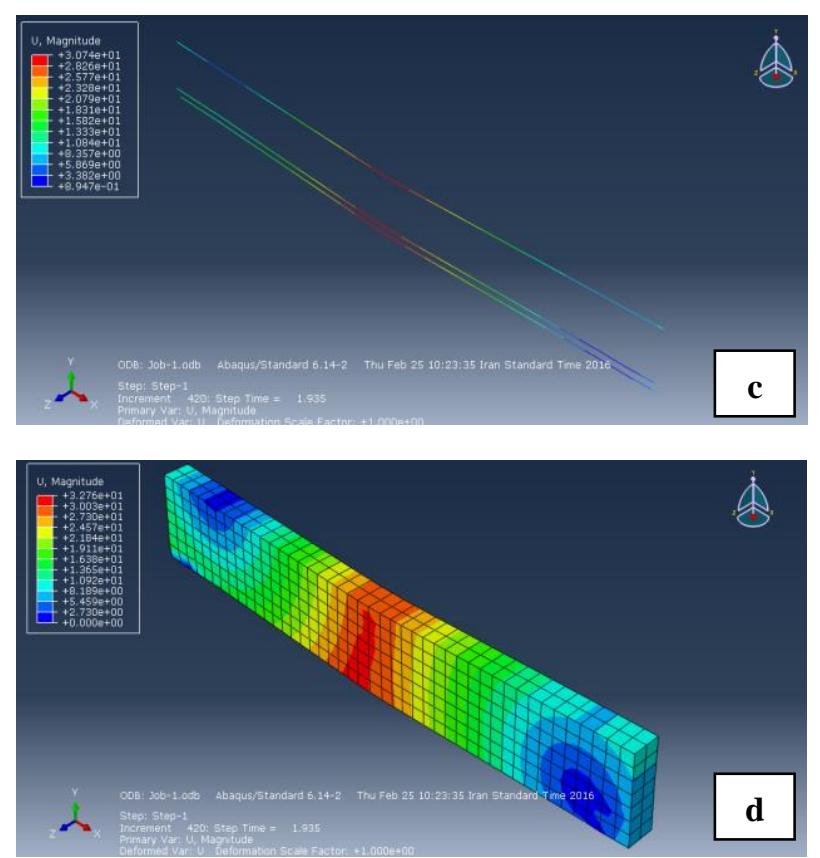

Figure 4. (a) contour of rods stress, (b) contour of concrete tension, (c) contour of displacement in rods, and (d) contour of displacement in concrete

\subsection{Impact of pre-stress in structural fatigue}

The effect of prestressing on structure fatigue has been investigated, and results are presented in Figure 5, and prestress beam in both the loading and unloading is more resistance. By increasing number of cycles, the loop within the diagram has been opened, which indicates that the structure enters the nonlinear phase and energy depreciation is increased. Insufficient asymmetry in the diagrams is due to the articulated fulcrum, and the more the inclination is to the receiver, the greater the symmetry of the diagram. As in Figure 5, in the first three cycles, the strength of the structure increases, hence, for the first cycle of prestress beam in the first peak, the strength is approximately $100 \mathrm{kN}$, and in the second and third cycles, 130 $\mathrm{kN}$ and $150 \mathrm{kN}$, respectively. But from the third cycle, both the peak resistance and the slope of the diagram are reduced, which means reducing the resistance and hardness. As can be seen the strength peak of prestress beam is reduced to $110 \mathrm{kN}$ and 100 $\mathrm{kN}$ in other cycles. For original beam, as seen in the first round, the resistance is approximately $100 \mathrm{kN}$ and in the second and third cycles, it is $118 \mathrm{kN}$ and $122 \mathrm{kN}$, respectively. The strength peak of the original beam decreases to $100 \mathrm{kN}$ and $90 \mathrm{kN}$ in subsequent cycles. The time diagrams for depreciated energy in 
the system are presented in Figure b5. At the beginning of the loading, structures are still in the nonlinear phase and the devices behave in the same way and their differences in energy depreciation increase. Therefore, energy depreciation in the prestress beam is more than the original beam (Figure 5).

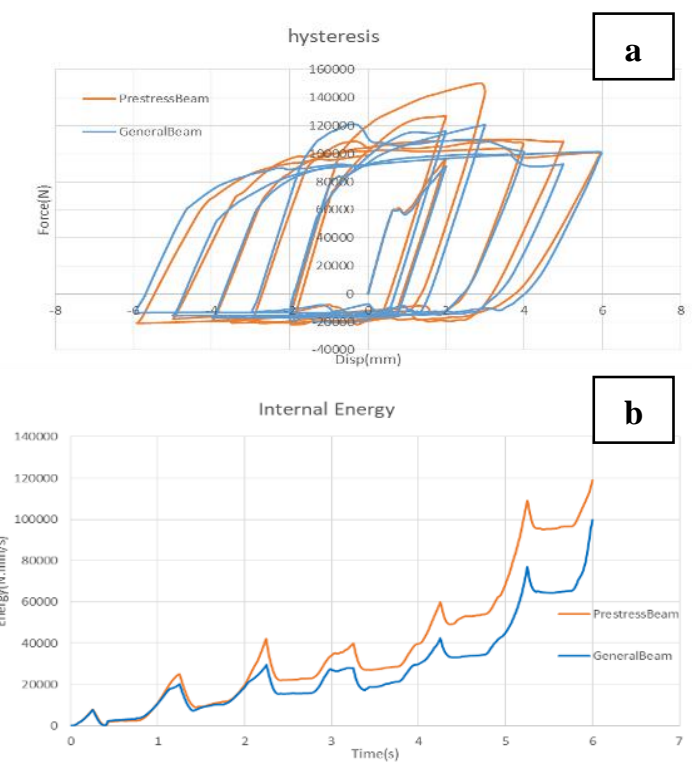

Figure 5. (a) a power-displacement hysteresis diagram, and (b) a timeline for amortized energy

\subsection{Comparison of the effect of prestressing and FRP}

According to hysteresis diagram in Fig. a6, in case of a linear phase structure, prestress works better than fatigue loads, this is also evident in the energy diagram (Figure b6); however, increasing cracks and entering the structure to nonlinear phase, and the more the loading cycle is, causes the greater the effect of FRP. In the first three cycles, the strength of the structure increases, in the first cycle, strength peak is approximately 100 $\mathrm{kN}$ and in the second and third cycles, it is $130 \mathrm{kN}$ and $150 \mathrm{kN}$, respectively. As you see, the strength peak of the prestressed beam is reduced to $110 \mathrm{kN}$ and $100 \mathrm{kN}$ in subsequent cycles. For reinforced beam with FRP sheets, strength peak is $90 \mathrm{kN}$ in the first cycle, and in the second and third cycles, $110 \mathrm{kN}$ and $130 \mathrm{kN}$, respectively. The strength peak of the reinforced beam with FRP sheets is reduced to $110 \mathrm{kN}$ and $90 \mathrm{kN}$ in subsequent cycles.

In Figure a7, the first three cycles of the prestressed and MIXBeam (having prestress effect and reinforced with FRP), they have the highest strength peak (about $150 \mathrm{kN}$ ) and reinforced with FRP sheets with the most strength.

In Figure b7, in the first three cycles of the prestress beams and MIXBeam (having prestress effect and reinforced with FRP), they have the highest energy depreciation (about 40,000 $\mathrm{N} . \mathrm{mm} / \mathrm{s}$ ), but by increasing number of loading cycles observed that beam reinforced with FRP sheets and MIXBeam (having both prestress effect and reinforced with FRP) with the highest amount of energy depreciation, which are $145,000 \mathrm{~N} . \mathrm{mm} / \mathrm{s}$ and $130,000 \mathrm{~N} . \mathrm{mm} / \mathrm{s}$. In case of using both prestress and FRP, the positive performance of the structure against fatigue load is reduced. The energy diagram in Figure b7 clearly illustrates this issue. Of course, this difference appears in many cycles, and at the beginning of the loading, the structure is still in linear phase, the two beams behave the same.

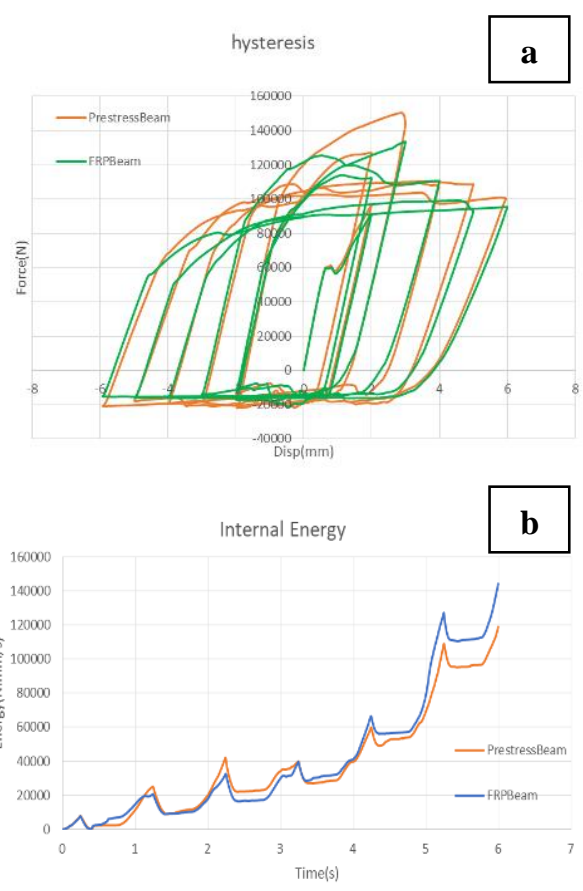

Figure 6. (a) The power-displacement hysteresis diagram; and (b) a timeline for the amortized energy
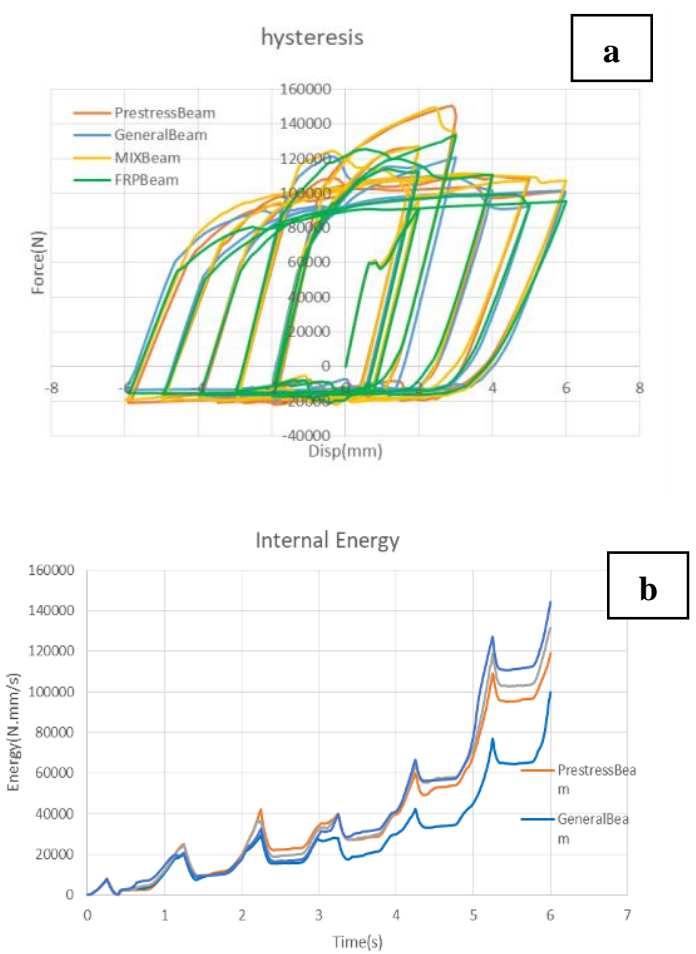

Figure 7. (a) The power-displacement hysteresis diagram; and (b) the timeline for amortized energy

\subsection{Evaluation of the effect of concrete compressive strength (fc) on the results}

In this section, the effect of concrete compressive strength (fc) on structural fatigue is shown. Until this level, for all samples, 
the compressive strength of the concrete ( $\mathrm{fc}$ ) is assumed to be $50 \mathrm{MPa}$. At this level, the compressive strength of the concrete (fc) is $25 \mathrm{MPa}$, and its results which have been obtained from the analysis of the samples are presented in Figure 8. As you see, in the first three cycles, the strength of the structure increases; in the first round of the peak, the strength is approximately $78 \mathrm{kN}$, and in the second and third cycles, it is $99 \mathrm{kN}$ and $117 \mathrm{kN}$, respectively. But from the third cycle, both the strength peak and slope of the diagram are reduced, which reduces the strength and hardness. The strength peak of the prestressed beam is reduced to $49 \mathrm{kN}$ and $43 \mathrm{kN}$ in subsequent cycles. For the original beam, in the first cycle, the strength peak is approximately $71 \mathrm{kN}$, and in the second and third cycles, $93 \mathrm{kN}$ and $101 \mathrm{kN}$, respectively. The strength of the original beam decreases to $84 \mathrm{kN}$ and $72 \mathrm{kN}$ in subsequent cycles.

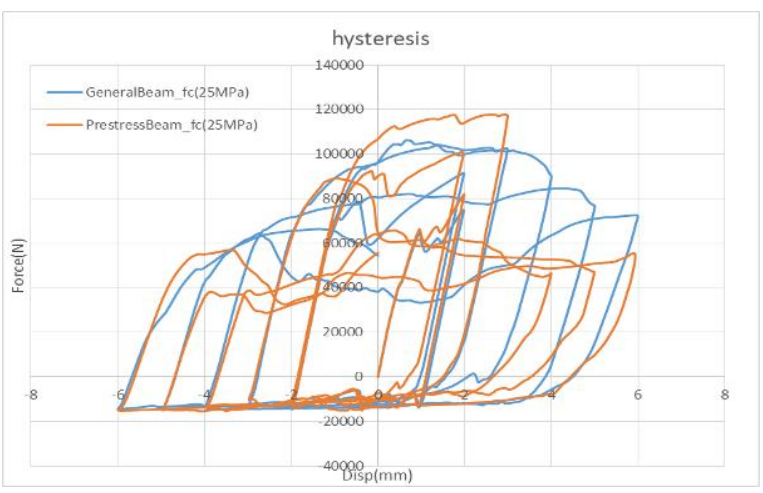

Figure 8. Power-displacement hysteresis diagram

The results of the prestressed beam analysis for concrete with different strengths have been compared, which are shown in hysteresis diagram in Figure 9, the compressive strength of the concrete (fc) is $50 \mathrm{MPa}$ which decreases from $149 \mathrm{kN}$ to 116 $\mathrm{kN}$ in the first three cycles. When concrete compressive strength (fc) is $25 \mathrm{Mpa}$ it reduces. This change is 22 percent of strength reduction.

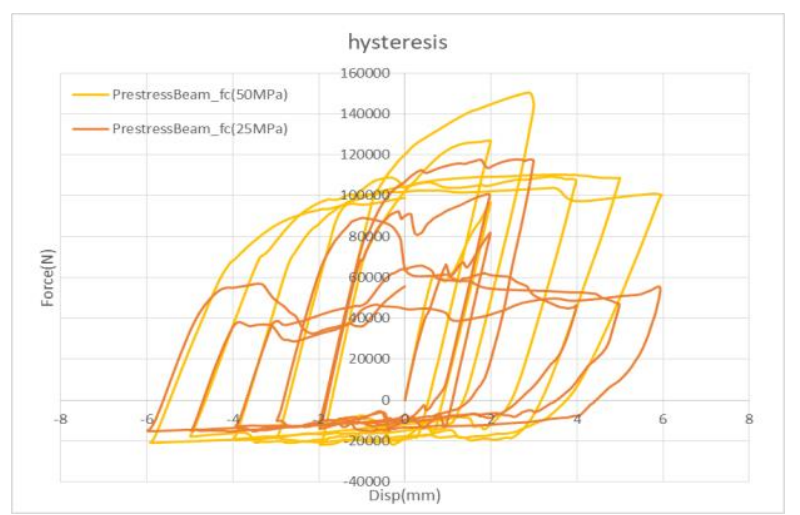

Figure 9. Power-displacement hysteresis diagram

The results of the prestressed beam analysis with a beam reinforced with FRP sheets have been compared, which are presented in Figure 10. The maximum strength of prestress beam is $117 \mathrm{MPa}$ and the maximum strength of the beam with FRP sheets is $105 \mathrm{MPa}$. Moreover, when the compressive strength of the concrete is $50 \mathrm{MPa}$, the prestress beam shows more resistance.

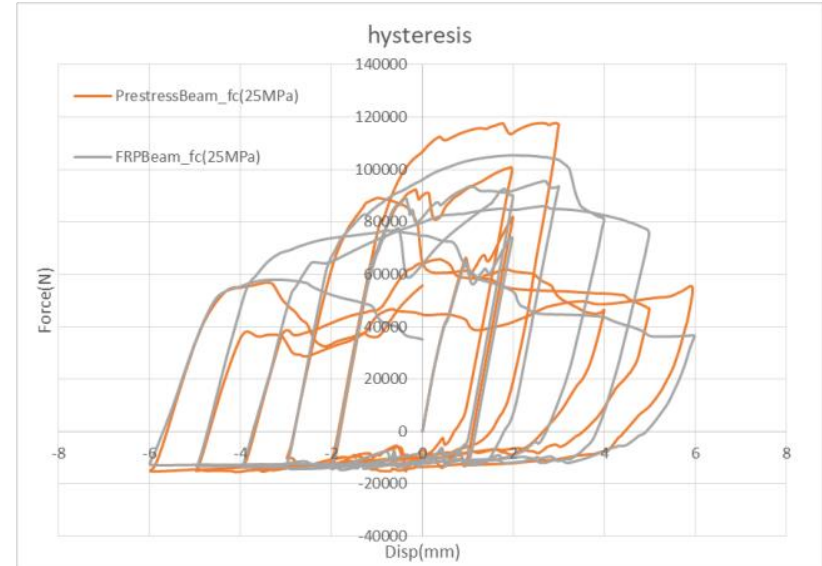

Figure 10. Power-displacement hysteresis diagram with a compressive strength of concrete (fc) equal with $25 \mathrm{Mpa}$

The results of the analysis of reinforced beam with FRP sheets by both strong concrete ( $\mathrm{fc}$ of $50 \mathrm{MPa}$ ) and weak concrete (fc of $25 \mathrm{MPa}$ ) have been investigated, which results are presented in Figure 11. Strength of the beam in weak concrete decreases from $132 \mathrm{kN}$ to $105 \mathrm{kN}$ in the first three cycles. This change is 20 percent of reduction of structural strength.

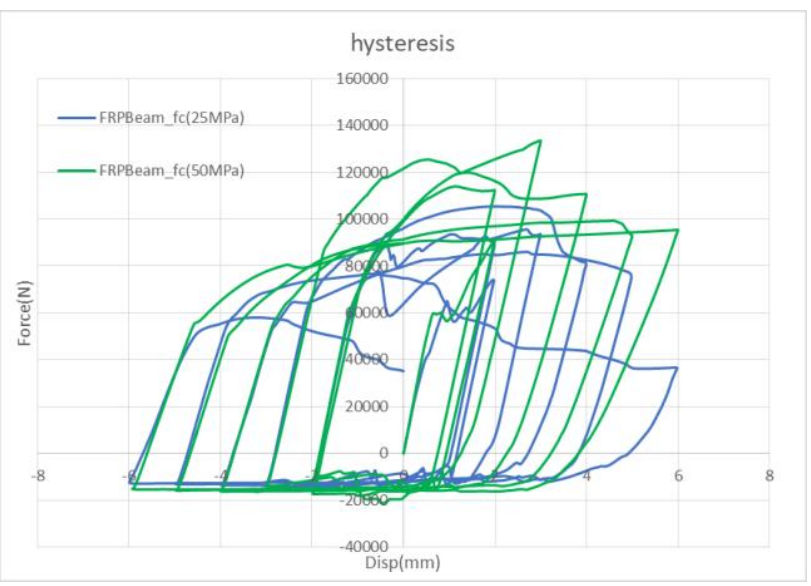

Figure 11. Power-displacement hysteresis diagram for the reinforced beam with FRP sheets

\section{RESULTS}

In this study, the effect of fatigue under reciprocating load with hysterical analysis of 4 concrete beam samples in a cyclic periodic history was studied and the following results were obtained:

1. The diagrams of the pre-stress effects on structural fatigue showed a higher strength in both loading and unloading of the beam. Moreover, by increasing number of cycles, the loop within the diagram has been opened, indicates that the structure enters the non-linear phase and depreciation of energy increases. Insufficient asymmetries in the diagrams are due to the articular fulcrum. As the backpack moves toward the receiver, the symmetry of the diagram becomes larger. Also, at the beginning of the loading, which structures still enter the nonlinear phase, the devices behave in the same way 
and their differences in energy depreciation increase.

2. In linear phase, the prestress behave better than fatigue loads (strength peak is more in the diagram). This is also evident in the energy diagram, but with increasing cracks and entering the structure to the nonlinear stage, the effect of FRP is greater since it leads to more energy depreciation in the structure; the longer the loading cycle is, the more FRP's effect.

3. It is noteworthy that prestress and FRP are both used, the positive performance of the structure against fatigue load is reduced compared with that used by FRP.

4. Comparing prestress beam with FRP reinforced beam was observed that by decreasing the compressive strength of concrete till $50 \%$, the prestress beam is more strength than FRP beam.

5. Comparing prestress beam with FRP reinforced beam was observed that by reducing the compressive strength of the concrete, $50 \%$ of depreciation energy by the prestress beam is almost twice as high as that of FRP sheets. Interestingly, in the case of a stronger concrete (fc of $50 \mathrm{MPa}$ ), this process is vice versa, i.e. reinforced beam with FRP sheets absorbs more energy during loading time.

6. The analysis of reinforced beam with FRP sheets has been shown, $50 \%$ reduction in the compressive strength of the concrete, $20 \%$ reduction in the structural strength and a $69 \%$ reduction in the energy absorption of the structure.

\section{References:}

Abdelatif, A. O., Owen, J. S., \& Hussein, M. F. (2015). Modelling the prestress transfer in pre-tensioned concrete elements. Finite Elements in Analysis and Design, 94, 47-63.

Alampalli, S. \& Lund, R., 2010. Estimating Fatigue Life of Bridge Components Using Measured Strains. Journal of Bridge Engineering, 11(6), pp. 725-736.

Balaguru, P., Nanni, A. \& Giancaspro, J., 2014. FRP composites for reinforced and prestressed concrete structures: A guide to fundamentals and design for repair and retrofit. CRC Press.

Bu, Z. Y., Ou, Y. C., Song, J. W., Zhang, N. S., \& Lee, G. C. (2015). Cyclic loading test of unbonded and bonded posttensioned precast segmental bridge columns with circular section. Journal of Bridge Engineering, 21(2), 04015043.

Dai, L., Wang, L., Zhang, J., \& Zhang, X., 2016. A global model for corrosion-induced cracking in prestressed concrete structures. Engineering Failure Analysis, 62, 263-275.

Dewit, N. (2012). A Composite Structural Steel and Prestressed Concrete Beam for Building Floor Systems.
Di Ludovico, M., Nanni, A., Prota, A., \& Cosenza, E., 2005. Repair of bridge girders with composites: Experimental and analytical validation. ACI Structural Journal, 102(5), p. 639.

Huang, L., Xu, L., Chi, Y., \& Xu, H., 2015. Experimental investigation on the seismic performance of steelpolypropylene hybrid fiber reinforced concrete columns. Construction and Building Materials, 87, 16-27.

Li, C., Hao, H., Zhang, X., \& Bi, K., 2018. Experimental study of precast segmental columns with unbonded tendons under cyclic loading. Advances in Structural Engineering, 21(3), 319334.

Maes, M. A., Wei, X., \& Dilger, W. H., 2001. Fatigue reliability of deteriorating prestressed concrete bridges due to stress corrosion cracking. Canadian Journal of Civil Engineering, 28(4), pp. 673-683.

Martí, J. V., Yepes, V., \& González-Vidosa, F., 2014. Memetic algorithm approach to designing precast-prestressed concrete road bridges with steel fiber reinforcement. Journal of Structural Engineering, 141(2), 04014114.

Nardone, F., Di Ludovico, M., y Basalo, F. J. D. C., Prota, A., \& Nanni, A., 2012. Tensile behavior of epoxy based FRP composites under extreme service conditions. Composites Part B: Engineering, 43(3), pp. 1468-1474.

Wada, A., Sakata, H., Nakano, K., Matsuzaki, Y., Tanabe, K., \& Machida, S., 2006. Study on Damage Controlled PrecastPrestressed Concrete Structure with P/C MILD-PRESSJOINTPart 1: Overview of P/C Mild-Press-Joint Building Construction and its Practical Applications. In Proceedings of the 2nd FIB Congress (Vol. 400).

Wolanski, A. J., 2004. Flexural behavior of reinforced and prestressed concrete beams using finite element analysis (Doctoral dissertation), marquette university, milwaukee, Wisconsin.

Zia, P., Kowalsky, M. J., Ellen, G. C., \& Longo, S. E., 2002. Fatigue performance of large-sized long-span prestressed concrete girders impaired by transverse cracks (No. FHWA/NC/2002-24). 